\title{
Carvacrol ameliorates inflammatory response in interleukin 1 $\beta$-stimulated human chondrocytes
}

\author{
YU XIAO, BING LI, JUN LIU and XINLONG MA \\ Joint Department, Tianjin Hospital, Tianjin 300211, P.R. China \\ Received July 11, 2016; Accepted July 11, 2017
}

DOI: $10.3892 / \mathrm{mmr} .2017 .8308$

\begin{abstract}
Carvacrol, a monoterpenic phenol present in Origanum vulgare (oregano) and Thymus vulgaris (thyme), possesses anti-inflammatory effects; however, little is known about the effects and underlying mechanism of carvacrol on chondrocytes in osteoarthritis (OA). The present study aimed to investigate the protective effects of carvacrol against inflammation in interleukin $1 \beta$ (IL-1 $\beta$ )-stimulated human chondrocytes. The results indicated that carvacrol inhibited nitric oxide (NO) and prostaglandin E2 (PGE2) production, and decreased the expression of inducible NO synthase (iNOS) and cyclooxygenase (COX-2). Carvacrol also suppressed the protein expression levels of matrix metalloproteinase (MMP)-3 and MMP-13 in IL-1 $\beta$-stimulated human OA chondrocytes. Furthermore, carvacrol suppressed the activation of nuclear factor (NF) $-\kappa B$ signaling pathway in IL-1 $\beta$-induced human chondrocytes. In conclusion, the present results demonstrated that carvacrol was able to inhibit IL-1 $\beta$-induced NO and PGE2 production, as well as iNOS, COX-2 and MMPs expression in human chondrocytes by suppressing the activation of $\mathrm{NF}-\kappa \mathrm{B}$ signaling pathway. Thus, carvacrol may have potential therapeutic functions for the treatment of OA.
\end{abstract}

\section{Introduction}

Osteoarthritis (OA) is a common chronic degenerative joint disease and is a leading cause of pain and disability in the adult population. In Asian countries, the incidence of OA in individuals aged $>65$ years, may increase from $6.8 \%$ in 2008 to $16.2 \%$ in 2040 (1). Risk factors of OA may be divided into person-level factors (age, gender, obesity, genetics and diet) and joint-level factors (injury, malalignment and abnormal loading of the joints), which interact in a complex manner (2). It is characterized by bone remodeling, synovium inflammation and cartilage loss (3). Although the management of OA has been diverse, including pharmacological therapy treatment

Correspondence to: Dr Yu Xiao, Joint Department, Tianjin Hospital, 406 Jiefang South Road, Hexi, Tianjin 300211, P.R. China E-mail: yuxiaojoint@126.com

Key words: carvacrol, osteoarthritis, chondrocytes, inflammation options, surgical interventions and orthopedic procedures $(4,5)$, there are no effective drug treatments that are able to reverse disease progression $(6,7)$. Therefore, the development of new therapeutic strategies that are effective and safe for OA treatment are required.

OA pathogenesis is complex and involves the interaction of numerous factors, and an increasing number of studies have suggested that inflammation serves a key role in the pathogenesis of OA (8-10). Chondrocytes secrete pro-inflammatory cytokines, such as interleukin-1 $\beta$ (IL-1 $\beta$ ) and tumor necrosis factor- $\alpha$ (TNF- $\alpha$ ), that may contribute to the progression of OA (11). IL-1 $\beta$ was reported to enhance the production of matrix metalloproteinases (MMPs) and to inhibit the synthesis of extracellular matrix (ECM), thus contributing the progression of OA $(12,13)$.

Carvacrol is a monoterpenic phenol that is present in Origanum vulgare (oregano) and Thymus vulgaris (thyme), which has been demonstrated to possess a spectrum of pharmacological activities, including antioxidative, analgesic, antihepatotoxic, antimicrobial and antitumoral $(14,15)$. In addition, a previous study confirmed its anti-inflammatory property. For example, carvacrol was reported to inhibit the levels of inflammatory cytokines and the expression of inducible nitric oxide synthase (iNOS) and cyclooxygenase (COX)-2 in ischemic cortical tissues (16). However, the effects and underlying mechanism of carvacrol on chondrocytes in OA remain unknown. The present study aimed to investigate the protective effects of carvacrol against inflammation in IL-1 $\beta$-stimulated human chondrocytes, and the results demonstrated that carvacrol pretreatment inhibited IL-1 $\beta$-induced nitric oxide (NO) and prostaglandin E2 (PGE2) production, and reduced the expression levels of iNOS, COX-2 and MMPs in human OA chondrocytes by suppressing the activation of the $\mathrm{NF}-\kappa \mathrm{B}$ signaling pathway. Thus, carvacrol may provide a potential therapeutic function for the treatment of OA.

\section{Materials and methods}

Normal human articular cartilage chondrocyte culture and treatment. Normal human articular cartilage was obtained from eight patients (4 men, 4 women; age 24-41 years) after death or from trauma in Tianjin Hospital (Tianjin, China). The normal donors were significantly younger whose articular cartilage had no degenerative changes. Written informed consent was 
obtained from the patients according to the terms of the Ethics Committee of Tianjin Hospital. Chondrocytes were isolated from cartilage as previously described (17). Briefly, cartilage fragments were digested with $0.25 \%$ trypsin for $15 \mathrm{~min}$ and incubated with $0.2 \%(\mathrm{v} / \mathrm{v})$ collagenase for $4 \mathrm{~h}$ at $37^{\circ} \mathrm{C}$. The resulting cells were maintained in Dulbecco's modified Eagle's medium (DMEM) supplemented with 10\% fetal bovine serum (both from HyClone; GE Healthcare Life Sciences, Logan, UT, USA), $100 \mathrm{U} / \mathrm{ml}$ penicillin and $100 \mu \mathrm{g} / \mathrm{ml}$ streptomycin (Sigma-Aldrich; Merck KGaA, Darmstadt, Germany) at $37^{\circ} \mathrm{C}$ and $5 \% \mathrm{CO}_{2}$ in a humidified incubator.

Human chondrocytes $\left(1 \times 10^{5}\right.$ cells/well) were pretreated with various concentrations of carvacrol $(0,1,5$ and $10 \mu \mathrm{g} / \mathrm{ml}$; Sigma-Aldrich; Merck KGaA) for $2 \mathrm{~h}$ and then co-incubated in the absence or presence of IL-1 $\beta(10 \mathrm{ng} / \mathrm{ml}$; Sigma-Aldrich; Merck KGaA) for $24 \mathrm{~h}$ at $37^{\circ} \mathrm{C}$.

Cell viability assay. Cell viability was measured by the MTT assay. Briefly, following treatments, human chondrocytes $\left(1 \times 10^{5}\right.$ cells/well) were incubated with MTT solution $\left(5 \mathrm{mg} / \mathrm{ml}\right.$; Sigma-Aldrich; Merck $\mathrm{KGaA}$ ) at $37^{\circ} \mathrm{C}$ for $4 \mathrm{~h}$; subsequently, the purple formazan crystals were dissolved using dimethyl sulfoxide by shaking at room temperature for $10 \mathrm{~min}$. Spectrophotometric absorbance was measured at $570 \mathrm{~nm}$ using a multifunctional microplate reader (Bio-Rad Laboratories, Inc., Hercules, CA, USA). All experiments were repeated at least three times.

Measurement of NO and PGE2 levels. Nitrite levels in the culture medium were detected by the Griess reaction as previously described (18). The level of PGE2 was evaluated using a ELISA kit (cat no. KHL1701; Invitrogen; Thermo Fisher Scientific, Inc., Waltham, MA, USA), according to the manufacture's protocol. All experiments were repeated at least three times.

Reverse transcription-quantitative polymerase chain reaction $(R T-q P C R)$. Total RNA was extracted from human chondrocytes $\left(1 \times 10^{6}\right.$ cells/well) using TRIzol reagent (Invitrogen; Thermo Fisher Scientific, Inc.), according to the manufacturer's instructions. First-strand cDNA was synthesized from total RNA $(1 \mu \mathrm{g})$ using the PrimeScript RT Reagent kit with gDNA Eraser (Takara Bio, Inc., Otsu, Japan). Subsequently, a 7500 Real-Time PCR system (Applied Biosystems; Thermo Fisher Scientific, Inc.) was used to conduct RT-qPCR using SYBR Premix Ex Taq II (Takara Bio, Inc.). Primers used in qPCR are listed as follows: iNOS forward, 5'-TTTCCAAGA CACACTTCACCA-3' and reverse, 5'-ATCTCCTTTGTTACC GCTTCC-3'; COX-2 forward, 5'-GAGAGATGTATCCTC CCACAGTCA-3' and reverse, 5'-GACCAGGCACCAGAC CAAAG-3'; MMP-3 forward, 5'-GCATTGGCTGAGTGA AAGAGACTGTATC-3' and reverse, 5'-ATGATGAACGAT GGACAGATGA-3'; MMP-13 forward, 5'-AGTAGTTCCAAA GGCTACAACTTGTTT-3' and reverse, 5'-GGAGTGGTC AAGCCCTAAGGA-3'; GAPDH forward, 5'-CTGGGCTAC ACTGAGCA-3' and reverse, 5'-AAGTGGTCGTTGAGG GCAATG-3'. GAPDH was used as a reference gene. The PCR amplification cycles were performed as follows: $30 \mathrm{sec}$ at $95^{\circ} \mathrm{C}$, followed by 40 cycles of $5 \mathrm{sec}$ at $95^{\circ} \mathrm{C}$ and $30 \mathrm{sec}$ at $60^{\circ} \mathrm{C}$. The $2^{-\Delta \Delta \mathrm{Ct}}$ method (19) was used to calculate relative
A

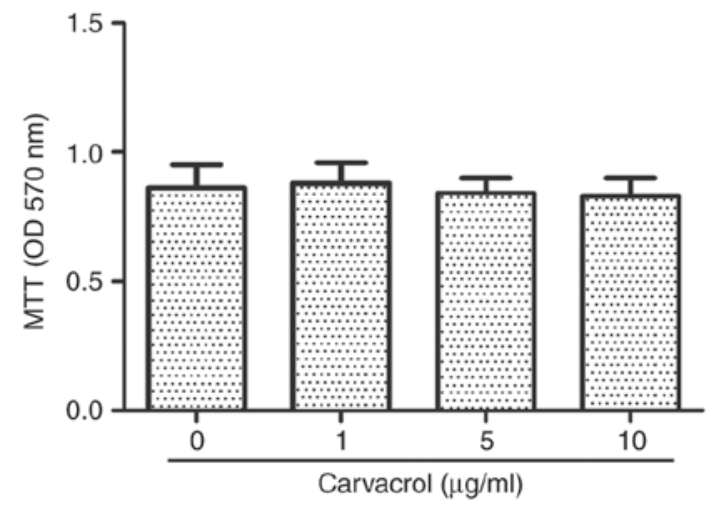

B

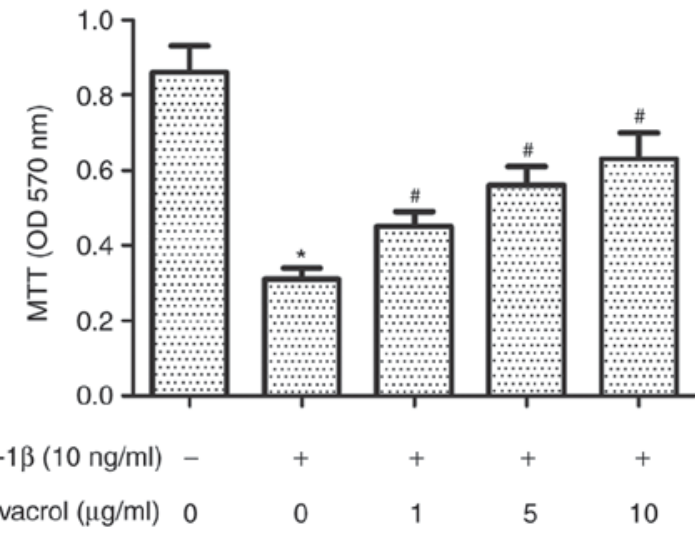

Figure 1. Effects of carvacrol on human osteoarthritis chondrocyte viability. (A) Human chondrocytes $\left(1 \times 10^{5}\right.$ cells/well) were cultured with various concentrations of carvacrol $(0,1,5$ and $10 \mu \mathrm{g} / \mathrm{ml})$ for $24 \mathrm{~h}$. Cell viability was detected by the MTT assay. (B) Human chondrocytes $\left(1 \times 10^{5}\right.$ cells/well) were pretreated with various concentrations $(0,1,510 \mu \mathrm{g} / \mathrm{ml})$ of carvacrol for $2 \mathrm{~h}$, followed by stimulation with or without IL-1 $\beta(10 \mathrm{ng} / \mathrm{ml})$ for $24 \mathrm{~h}$. Cell viability was detected by the MTT assay. All experiments were repeated at least three times. Data are presented as the mean \pm standard deviation; ${ }^{*} \mathrm{P}<0.05$ vs. control group; ${ }^{\#} \mathrm{P}<0.05$ vs. IL-1 $\beta$ group. IL, interleukin; OD, optical density.

changes in gene expression. All experiments were repeated at least three times.

Western blot analysis. Human chondrocytes $\left(1 \times 10^{6}\right.$ cells/well) were lysed in radioimmunoprecipitation assay buffer supplemented with protease and phosphatase inhibitor mixtures (Sigma-Aldrich; Merck KGaA). Protein concentrations were determined using a Bradford assay (Bio-Rad Laboratories, Inc.). Protein lysates $(30 \mu \mathrm{g})$ were separated by $10 \%$ SDS-PAGE and transferred to polyvinylidene fluoride membranes (both from Bio-Rad Laboratories, Inc.). Membranes were blocked in 5\% non-fat milk for $2 \mathrm{~h}$ at room temperature and then incubated with rabbit anti-human iNOS (1:500; ab3523), COX-2 (1:500; ab52237), MMP-3 (1:500; ab53015), MMP-13 (1:3,000; ab39012), NF-кB p65 $(1: 50,000 ; \mathrm{ab} 32536)$ and IкB $\alpha$ primary antibodies $(1: 1,000$; ab32518; all from Abcam, Cambridge, UK) overnight at $4^{\circ} \mathrm{C}$. Following washing with TBS containing $0.1 \%$ Tween-20 (TBST; Sigma-Aldrich; Merck KGaA), membranes were incubated with horseradish peroxidase-conjugated secondary goat anti-rabbit immunoglobulin $\mathrm{G}$ antibodies (1:1,000; sc-2922; Santa Cruz Biotechnology, Inc., Dallas, TX, USA) at room temperature for $1 \mathrm{~h}$. Membranes were 

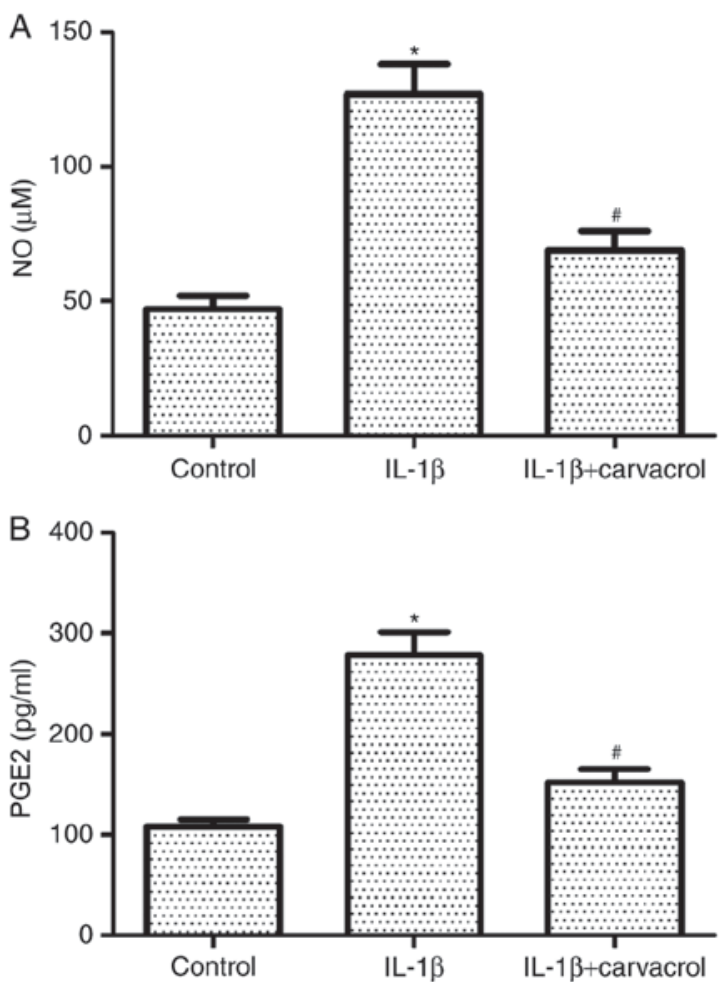

Figure 2. Carvacrol inhibits IL-1 $\beta$-induced NO and PGE2 production in osteoarthritis chondrocytes. Human chondrocytes at $\left(1 \times 10^{5}\right.$ cells/well) were pretreated with or without carvacrol $(10 \mu \mathrm{g} / \mathrm{ml})$ for $2 \mathrm{~h}$, followed by stimulation with IL-1 $\beta(10 \mathrm{ng} / \mathrm{ml})$ for $24 \mathrm{~h}$. (A) NO production was determined using the Griess reagent. (B) PGE2 production was determined using a commercial ELISA kit. All experiments were repeated at least three times. Data are presented as the mean \pm standard deviation; ${ }^{*} \mathrm{P}<0.05$ vs. control group; ${ }^{\#} \mathrm{P}<0.05$ vs. IL-1 $\beta$ group. IL, interleukin; NO, nitric oxide; PGE2, prostaglandin E2.

washed with TBST buffer, and immunoreactivity was detected with Enhanced Chemiluminescence reagent (GE Healthcare Life Sciences) and quantified by the Quantity One (Bio-Rad Laboratories, Inc.) version 5.2 software. $\beta$-actin was used as the internal control. All experiments were repeated at least three times.

Statistical analysis. Statistical analyses were performed using SPSS 13.0 software (SPSS, Inc., Chicago, IL, USA). Data are expressed as the mean \pm standard deviation. One-way analysis of variance followed by Newman-Keuls post-hoc test was used for the statistical comparison of multiple groups. Results from two groups were evaluated using Student's t-test. $\mathrm{P}<0.05$ was considered to indicate a statistically significant difference.

\section{Results}

Effects of carvacrol on human OA chondrocyte viability. Carvacrol cytotoxicity on chondrocyte viability was examined by MTT assay. Compared with untreated chondrocytes, the various treatments with carvacrol at concentrations between 1 and $10 \mu \mathrm{g} / \mathrm{ml}$ did not significantly affect cell viability (Fig. 1A). Treatment with IL-1 $\beta(10 \mathrm{ng} / \mathrm{ml})$ significantly reduced cell viability (Fig. 1B); whereas, pretreatment with carvacrol reversed the effects of IL-1 $\beta$ in a concentration-dependent
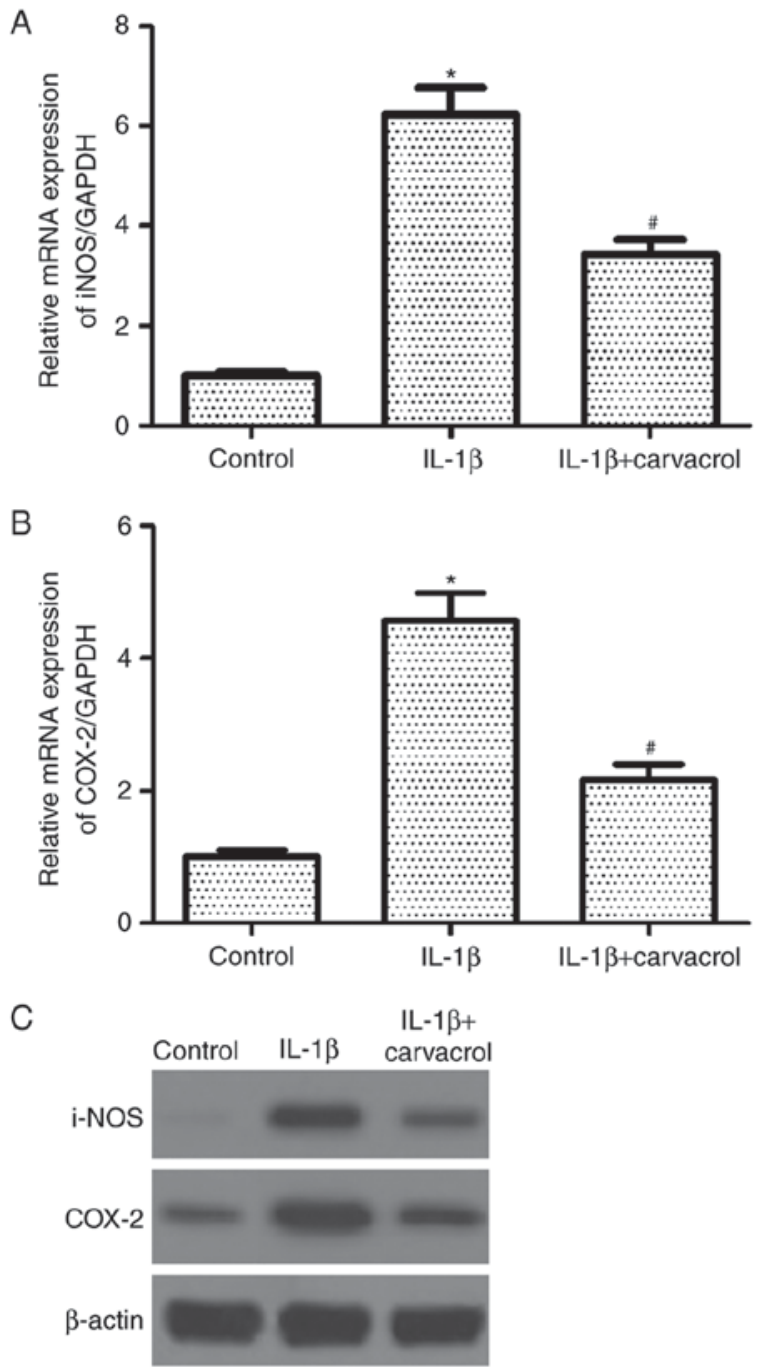

Figure 3. Carvacrol inhibits IL-1 $\beta$-induced iNOS and COX-2 expression in OA chondrocytes. Human chondrocytes $\left(1 \times 10^{5}\right.$ cells/well) were pretreated with or without carvacrol $(10 \mu \mathrm{g} / \mathrm{ml})$ for $2 \mathrm{~h}$, followed by stimulation with IL-1 $\beta(10 \mathrm{ng} / \mathrm{ml})$ for $24 \mathrm{~h}$. mRNA expression levels of (A) iNOS and (B) COX-2 were evaluated by reverse transcription-quantitative polymerase chain reaction. (C) Protein expression levels of iNOS and COX-2 were evaluated by western blotting. All experiments were repeated at least three times. Data are presented as the mean \pm standard deviation; ${ }^{*} \mathrm{P}<0.05$ vs. control group; ${ }^{\#} \mathrm{P}<0.05$ vs. IL-1 $\beta$ group. COX, cyclooxygenase; IL, interleukin; iNOS, inducible NO synthase.

manner (Fig. 1B). The highest inhibition was observed with $10 \mu \mathrm{g} / \mathrm{ml}$ carvacrol treatment. This concentration of carvacrol was used in the following experiment.

Carvacrol inhibits $I L-1 \beta$-induced $N O$ and PGE2 production in OA chondrocytes. The effects of carvacrol on NO and PGE2 production in IL-1 $\beta$-induced chondrocytes were also investigated. IL-1 $\beta$ treatment significantly induced the production of NO and PGE2 in OA chondrocytes (Fig. 2), and these increased levels of expression were significantly inhibited in cells co-treated with carvacrol.

Carvacrol inhibits IL-1 $\beta$-induced iNOS and COX-2 expression in $O A$ chondrocytes. Western blot analysis was used to determine the effects of carvacrol on iNOS and COX-2 expression in human chondrocytes stimulated with IL-1 $\beta$. The 
A

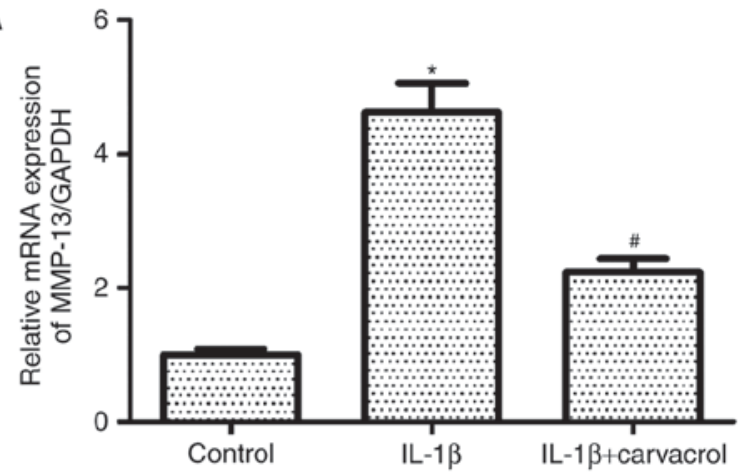

B

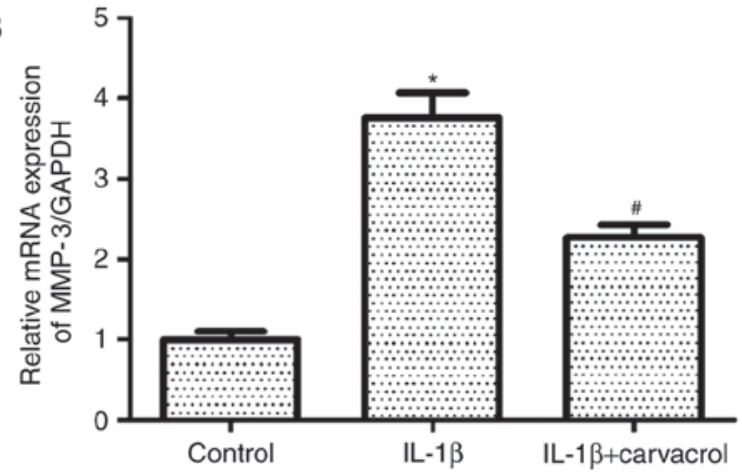

C

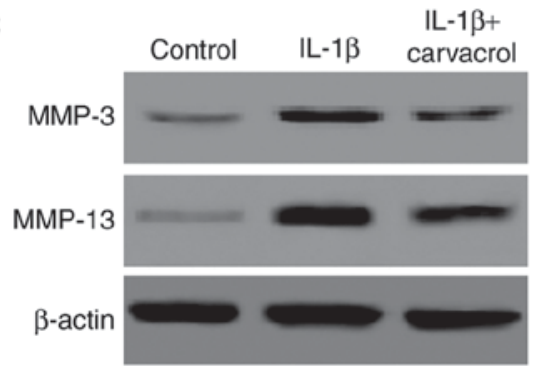

Figure 4. Carvacrol inhibits IL-1 $\beta$-induced MMP-3 and MMP-13 expression in OA chondrocytes. Human chondrocytes $\left(1 \times 10^{5}\right.$ cells/well) were pretreated with or without carvacrol $(10 \mu \mathrm{g} / \mathrm{ml})$ for $2 \mathrm{~h}$, followed by stimulation with IL-1 $\beta(10 \mathrm{ng} / \mathrm{ml})$ for $24 \mathrm{~h}$. mRNA expression levels of (A) MMP-13 and (B) MMP-3 were evaluated by reverse transcription-quantitative polymerase chain reaction. (C) The protein expression levels of MMP-3 and MMP-13 were evaluated by western blotting. All experiments were repeated at leas three times. Data are presented as the mean \pm standard deviation; ${ }^{*} \mathrm{P}<0.05$ vs. control group; ${ }^{\#} \mathrm{P}<0.05$ vs. IL-1 $\beta$ group. IL, interleukin; MMP, matrix metalloproteinase.

mRNA and protein expression levels of iNOS and COX-2 were markedly increased following IL-1 $\beta$ incubation compared with untreated controls (Fig. 3). By contrast, chondrocytes that were co-treated with carvacrol exhibited a notable decrease in iNOS and COX-2 expressions compared with IL-1 $\beta$-treated OA chondrocytes.

Carvacrol inhibits IL-1 $\beta$-induced MMP-3 and MMP-13 expression in $O A$ chondrocytes. A number of studies have demonstrated that MMPs serve crucial roles in the initiation and progression of OA (20-22). Therefore, the effects of carvacrol on MMP-3 and MMP-13 expression in IL-1 $\beta$-induced chondrocytes were examined. RT-qPCR analysis results demonstrated that the mRNA expression levels of MMP-13 and MMP-3 generated in IL-1 $\beta$-induced chondrocytes
A

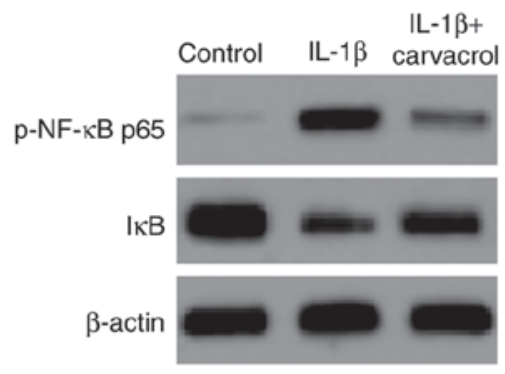

B

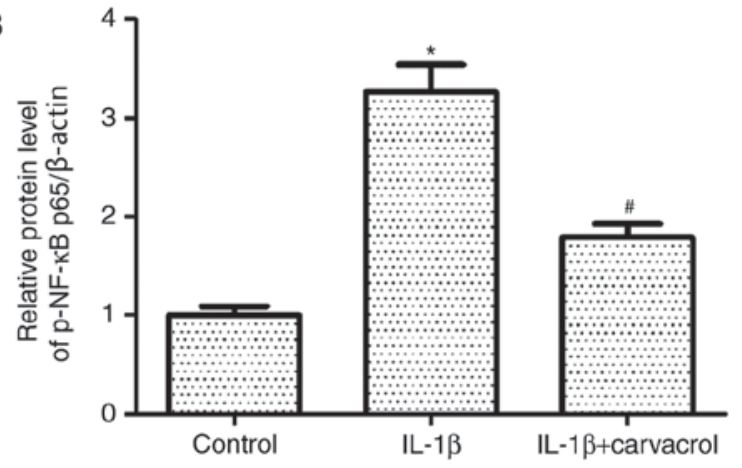

C

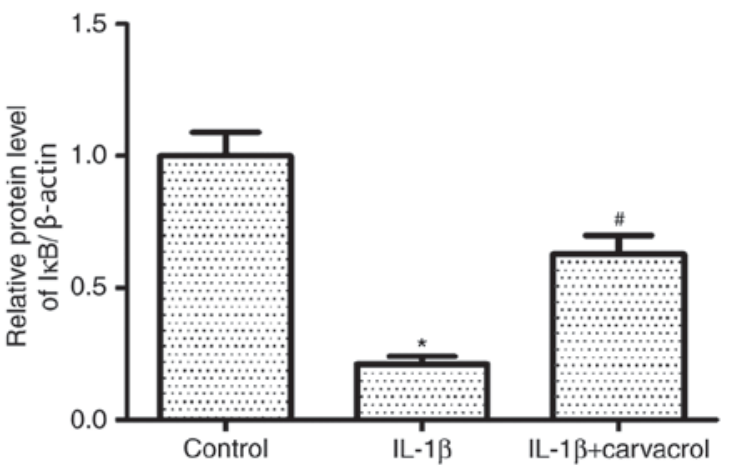

Figure 5. Carvacrol inhibits the activation of NF- $\mathrm{KB}$ signaling pathway in chondrocytes. Human chondrocytes $\left(1 \times 10^{5}\right.$ cells/well) were pretreated with or without carvacrol $(10 \mu \mathrm{g} / \mathrm{ml})$ for $2 \mathrm{~h}$, followed by stimulation with IL-1 $\beta$ $(10 \mathrm{ng} / \mathrm{ml}$ ) for $24 \mathrm{~h}$. (A) p-NF- $\kappa \mathrm{B}$ p 65 and $\mathrm{I} \kappa \mathrm{B} \alpha$ protein expression levels were evaluated by western blotting. Quantification of protein expression levels was performed by calculating the band density ratio of (B) $\mathrm{p}-\mathrm{NF}-\kappa \mathrm{B} \mathrm{p} 65 / \beta$-actin or $(C) I \kappa B \alpha / \beta$-actin. All experiments were repeated at least three times. Data are presented as the mean \pm standard deviation. ${ }^{*} \mathrm{P}<0.05$ vs. control group; ${ }^{\#} \mathrm{P}<0.05$ vs. IL- $1 \beta$ group. I $\mathrm{B} \alpha, \mathrm{NF}-\kappa \mathrm{B}$ inhibitor $\alpha$; IL, interleukin; NF, nuclear factor; $\mathrm{p}$, phosphorylated.

increased significantly compared with controls (Fig. 4A and B, respectively). However, pretreatment with carvacrol greatly inhibited these IL-1 $\beta$-induced effects. Similarly, western blot analysis demonstrated that carvacrol was able to suppress IL-1 $\beta$-induced MMP-3 and MMP-13 protein expression in OA chondrocytes (Fig. 4C).

Carvacrol inhibits the activation of nuclear factor $(N F)-\kappa B$ signaling pathway in chondrocytes. Activation of NF- $\kappa \mathrm{B}$ signaling pathway has been reported to participate in inflammation in OA (23). Therefore, the effects of carvacrol on NF- $\kappa \mathrm{B}$ activation in human chondrocytes stimulated with IL- $1 \beta$ were investigated. Western blot analysis data revealed that IL-1 $\beta$ treatment significantly increased the protein expression level of phosphorylated-NF-kB p65 and reduced the protein expression level of $\mathrm{I} \kappa \mathrm{B} \alpha$ in chondrocytes compared with untreated 
chondrocytes (Fig. 5). Notably, co-treatment with carvacrol significantly decreased the IL- $1 \beta$-induced expression of $\mathrm{NF}-\kappa \mathrm{B}$ in chondrocytes and increased the protein expression level of $\mathrm{I} \kappa \mathrm{B} \alpha$.

\section{Discussion}

A number of previous studies have reported that carvacrol possesses anti-inflammatory effects (24-27). Results from the present study indicated that carvacrol inhibited NO and PGE2 production, as well as decreased iNOS and COX-2 expression. Carvacrol was also demonstrated to suppress the protein expression levels of MMP-3 and MMP-13 in IL-1 $\beta$-stimulated human OA chondrocytes. Furthermore, carvacrol suppressed the activation of $\mathrm{NF}-\kappa \mathrm{B}$ signaling pathway in IL-1 $\beta$-induced human chondrocytes.

IL-1 $\beta$ treatment has been widely used to mimic the microenvironment of OA in in vitro studies (28-30); in the present study, IL-1 $\beta$-induced human OA chondrocytes were used as a model to investigate the protective effects of carvacrol on human chondrocytes, and the results suggested that pretreatment with carvacrol was able to reverse IL-1 $\beta$-reduced cell viability.

NO has been demonstrated to serve a pivotal role in the development of OA (31). It is produced by iNOS in several types of cells, including chondrocytes (32). PGE2 is an inflammatory mediator that is elevated by COX-2 (33). In addition, previous studies have reported that IL-1 $\beta$ was able to induce iNOS and COX-2 expression in chondrocytes, which led to elevated production of NO and PGE2, respectively $(34,35)$. The present study observed that carvacrol treatment inhibited NO and PGE2 production, as well as decreased iNOS and COX-2 expression in IL- $1 \beta$-stimulated human OA chondrocytes. These results are in agreement with previous studies, which reported that carvacrol significantly downregulated the expression levels of TNF- $\alpha$, IL- 6 , iNOS and COX-2 in D-galactosamine-induced hepatotoxic rats (36).

An increasing number of studies have indicated that MMPs may also be involved in the progression of OA $(22,37,38)$. For example, MMP-3 was reported to induce inflammation by activating various pro-MMPs and the cleavage of extracellular components (39). MMP-13 serves a crucial role in the degradation of collagens, proteoglycans and other ECM macromolecules in cartilage (40). Additional studies have demonstrated that IL-1 $\beta$ was able to upregulate the expression of MMPs in chondrocytes (41-43). The present study observed that carvacrol co-treatment suppressed IL-1 $\beta$-induced MMP-3 and MMP-13 protein expression in OA chondrocytes. These results suggested that carvacrol exhibited chondroprotective activity by downregulating MMP expression in vitro.

The NF- $\kappa$ B signaling pathway serves an important role in OA pathogenesis (44-46). Stimulation by inflammatory mediators such as IL-1 $\beta$ leads to the phosphorylation and degradation of the inhibitory subunit, which allows the active $\mathrm{NF}-\kappa \mathrm{B}$ complex to translocate into nucleus and induced the expression of various inflammation-related genes that regulate the synthesis of cytokines, chemokines and adhesion molecules (47). It was reported previously that the $\mathrm{NF}-\kappa \mathrm{B}$ inhibitor, pyrrolidine dithiocarbamate, decreased IL-1 $\beta$-induced MMP-3 and MMP-13 production in human chondrocytes (44). A recent study using ischemic cortical tissues confirmed that carvacrol treatment was able to suppress the ischemia/reperfusion-induced increase in nuclear $\mathrm{NF}-\kappa \mathrm{B}$ p65 protein expression in (16). Similarly, results from the present study revealed that pretreatment with carvacrol significantly inhibited IL- $1 \beta$-induced NF- $\kappa \mathrm{B}$ activation in OA chondrocytes. These data suggested that carvacrol may inhibit IL-1 $\beta$-induced inflammation in chondrocytes by suppressing the activation of the $\mathrm{NF}-\kappa \mathrm{B}$ signaling pathway.

In conclusion, the present results demonstrated that carvacrol pretreatment was able to inhibit IL-1 $\beta$-induced NO and PGE2 production, as well as reduced the expression levels of iNOS, COX-2, MMPs in human OA chondrocytes by suppressing the activation of $\mathrm{NF}-\kappa \mathrm{B}$ signaling pathway. Thus, carvacrol may provide a potential therapeutic function for the treatment of OA.

\section{References}

1. Miller ME, Rejeski WJ, Messier SP and Loeser RF: Modifiers of change in physical functioning in older adults with knee pain. The Observational Arthritis Study in Seniors (OASIS). Arthritis Rheum 45: 331-339, 2001

2. Palazzo C, Nguyen C, Lefevre-Colau MM, Rannou F and Poiraudeau S: Risk factors and burden of osteoarthritis. Ann Phys Rehabil Med 59: 134-138, 2016.

3. Loeser RF, Goldring SR, Scanzello CR and Goldring MB: Osteoarthritis: A disease of the joint as an organ. Arthritis Rheum 64: 1697-1707, 2012.

4. Pulsatelli L, Addimanda O, Brusi V, Pavloska B and Meliconi R: New findings in osteoarthritis pathogenesis: Therapeutic implications. Ther Adv Chronic Dis 4: 23-43, 2013.

5. Thysen S, Luyten FP and Lories RJ: Targets, models and challenges in osteoarthritis research. Dis Model Mech 8: 17-30, 2015.

6. Lawrence RC, Felson DT, Helmick CG, Arnold LM, Choi H, Deyo RA, Gabriel S, Hirsch R, Hochberg MC, Hunder GG, et al: Estimates of the prevalence of arthritis and other rheumatic conditions in the United States: Part II. Arthritis Rheum 58: 26-35, 2008.

7. Cheng DS and Visco CJ: Pharmaceutical therapy for osteoarthritis. PM R 4 (5 Suppl): S82-S88, 2012.

8. Pelletier JP, Martel-Pelletier J and Abramson SB: Osteoarthritis, an inflammatory disease: Potential implication for the selection of new therapeutic targets. Arthritis Rheum 44: 1237-1247, 2001.

9. Goldring MB and Otero M: Inflammation in osteoarthritis. Curr Opin Rheum 23: 471-478, 2011.

10. Haywood L, McWilliams DF, Pearson CI, Gill SE, Ganesan A, Wilson D and Walsh DA: Inflammation and angiogenesis in osteoarthritis. Arthritis Rheum 48: 2173-2177, 2003.

11. López-Armada MJ, Caramés B, Lires-Deán M, Cillero-Pastor B, Ruiz-Romero C, Galdo F and Blanco FJ: Cytokines, tumor necrosis factor-alpha and interleukin-1beta, differentially regulate apoptosis in osteoarthritis cultured human chondrocytes. Osteoarthritis Cartilage 14: 660-669, 2006.

12. Mengshol JA, Vincenti MP, Coon CI, Barchowsky A and Brinckerhoff CE: Interleukin-1 induction of collagenase 3 (matrix metalloproteinase 13) gene expression in chondrocytes requires $\mathrm{p} 38$, c-jun $\mathrm{N}$-terminal kinase, and nuclear factor kappaB: Differential regulation of collagenase 1 and collagenase 3 . Arthritis Rheum 43: 801-811, 2000.

13. Pujol JP, Chadjichristos C, Legendre F, Bauge C, Beauchef G, Andriamanalijaona R, Galera P and Boumediene K: Interleukin-1 and transforming growth factor-betal as crucial factors in osteoarthritic cartilage metabolism. Connect Tissue Res 49: 293-297, 2008.

14. Melusova M, Slamenova D, Kozics K, Jantova S and Horvathova E: Carvacrol and rosemary essential oil manifest cytotoxic, DNA-protective and pro-apoptotic effect having no effect on DNA repair. Neoplasma 61: 690-699, 2014.

15. Bakır M, Geyikoglu F, Colak S, Turkez H, Bakır TO and Hosseinigouzdagani $\mathrm{M}$ : The carvacrol ameliorates acute pancreatitis-induced liver injury via antioxidant response. Cytotechnology 68: 1131-1146, 2016. 
16. Li Z, Hua C, Pan X, Fu X and Wu W: Carvacrol exerts neuroprotective effects via suppression of the inflammatory response in middle cerebral artery occlusion rats. Inflammation 39: $1566-1572,2016$

17. Akhtar N, Rasheed Z, Ramamurthy S, Anbazhagan AN, Voss FR and Haqqi TM: MicroRNA-27b regulates the expression of matrix metalloproteinase 13 in human osteoarthritis chondrocytes. Arthritis Rheum 62: 1361-1371, 2010.

18. Marcu KB, Otero M, Olivotto E, Borzi RM and Goldring MB NF-kappaB signaling: Multiple angles to target OA. Curr Drug Targets 11: 599-613, 2010.

19. Livak KJ and Schmittgen TD: Analysis of relative gene expression data using real-time quantitative PCR and the 2(-Delta Delta C(T)) method. Methods 25: 402-408, 2001.

20. Martel-Pelletier J, Boileau C, Pelletier JP and Roughley PJ: Cartilage in normal and osteoarthritis conditions. Best Pract Res Clin Rheumatol 22: 351-384, 2008.

21. Aida Y, Maeno M, Suzuki N, Shiratsuchi H, Motohashi M and Matsumura H: The effect of IL-1beta on the expression of matrix metalloproteinases and tissue inhibitors of matrix metalloproteinases in human chondrocytes. Life Sci 77: 3210-3221, 2005.

22. Li H, Li L, Min J, Yang H, Xu X, Yuan Y and Wang D: Levels of metalloproteinase (MMP-3, MMP-9), NF-kappaB ligand (RANKL), and nitric oxide (NO) in peripheral blood of osteoarthritis (OA) patients. Clin Lab 58: 755-762, 2012.

23. Marcu KB, Otero M, Olivotto E, Borzi RM and Goldring MB: NF-kappaB signaling: Multiple angles to target OA. Curr Drug Targets 11: 599-613, 2010.

24. Landa P, Kokoska L, Pribylova M, Vanek T and Marsik P: In vitro anti-inflammatory activity of carvacrol: Inhibitory effect on COX-2 catalyzed prostaglandin E(2) biosynthesis. Arch Pharm Res 32: 75-78, 2009.

25. Silva FV, Guimarães AG, Silva ER, Sousa-Neto BP, Machado FD, Quintans-Júnior LJ, Arcanjo DD, Oliveira FA and Oliveira RC: Anti-inflammatory and anti-ulcer activities of carvacrol, a monoterpene present in the essential oil of oregano. J Med Food 15: 984-991, 2012

26. Lima Mda S, Quintans-Júnior LJ, de Santana WA Martins Kaneto C, Pereira Soares MB and Villarreal CF: Anti-inflammatory effects of carvacrol: Evidence for a key role of interleukin-10. Eur J Pharmacol 699: 112-117, 2013.

27. Arigesavan K and Sudhandiran G: Carvacrol exhibits anti-oxidant and anti-inflammatory effects against 1,2-dimethyl hydrazine plus dextran sodium sulfate induced inflammation associated carcinogenicity in the colon of Fischer 344 rats Biochem Biophys Res Commun 461: 314-320, 2015.

28. Vincenti MP and Brinckerhoff CE: Early response genes induced in chondrocytes stimulated with the inflammatory cytokine interleukin-lbeta. Arthritis Res 3: 381-388, 2001.

29. Chen WP, Tang JL, Bao JP, Hu PF, Shi ZL and Wu LD: Anti-arthritic effects of chlorogenic acid in interleukin-1 $\beta$-induced rabbit chondrocytes and a rabbit osteoarthritis model. Int Immunopharmacol 11: 23-28, 2011.

30. Han G, Shao H, Zhu X, Wang G, Liu F, Wang F, Ling P and Zhang T: The protective effect of xanthan gum on interleukin-1 $\beta$ induced rabbit chondrocytes. Carbohydr Polym 89: 870-875, 2012.

31. Nakagawa S, Arai Y, Mazda O, Kishida T, Takahashi KA, Sakao K, Saito M, Honjo K, Imanishi J and Kubo T: $\mathrm{N}$-acetylcysteine prevents nitric oxide-induced chondrocyte apoptosis and cartilage degeneration in an experimental model of osteoarthritis. J Orthop Res 28: 156-163, 2010.

32. Aktan F: iNOS-mediated nitric oxide production and its regulation. Life Sci 75: 639-653, 2004.
33. Abramson SB: The role of COX-2 produced by cartilage in arthritis. Osteoarthritis Cartilage 7: 380-381, 1999.

34. Ying X, Chen X, Cheng S, Shen Y, Peng L and Xu HZ: Piperine inhibits IL- $\beta$ induced expression of inflammatory mediators in human osteoarthritis chondrocyte. Int Immunopharmacol 17: 293-299, 2013

35. Chowdhury TT, Bader DL and Lee DA: Dynamic compression counteracts IL-1beta induced iNOS and COX-2 activity by human chondrocytes cultured in agarose constructs. Biorheology 43 413-429, 2006.

36. Aristatile B, Al-Assaf AH and Pugalendi KV: Carvacrol suppresses the expression of inflammatory marker genes in D-galactosamine-hepatotoxic rats. Asian Pac J Trop Med 6: 205-211, 2013.

37. Dreier R, Grässel S, Fuchs S, Schaumburger J and Bruckner P Pro-MMP-9 is a specific macrophage product and is activated by osteoarthritic chondrocytes via MMP-3 or a MT1-MMP/MMP-13 cascade. Exp Cell Res 297: 303-312, 2004.

38. Takaishi H, Kimura T, Dalal S, Okada Y and D'Armiento J: Joint diseases and matrix metalloproteinases: A role for MMP-13. Curr Pharm Biotechnol 9: 47-54, 2008.

39. Fosang AJ, Last K, Knäuper V, Murphy G and Neame PJ: Degradation of cartilage aggrecan by collagenase-3 (MMP-13). FEBS Lett 380: 17-20, 1996.

40. Johansson N, Saarialho-Kere U, Airola K, Herva R, Nissinen L, Westermarck J, Vuorio E, Heino J and Kähäri VM: Collagenase-3 (MMP-13) is expressed by hypertrophic chondrocytes, periosteal cells, and osteoblasts during human fetal bone development. Dev Dyn 208: 387-397, 1997.

41. Ahmed S, Wang N, Hafeez BB, Cheruvu VK and Haqqi TM: Punica granatum L. extract inhibits IL-1beta-Induced expression of matrix metalloproteinases by inhibiting the activation of MAP kinases and NF-kappaB in human chondrocytes in vitro. J Nutr 135: 2096-2102, 2005.

42. Aida Y, Maeno M, Suzuki N, Shiratsuchi H, Motohashi M and Matsumura $\mathrm{H}$ : The effect of IL-1beta on the expression of matrix metalloproteinases and tissue inhibitors of matrix metalloproteinases in human chondrocytes. Life Sci 77: 3210-3221, 2005.

43. Woodell-May J, Matuska A, Oyster M, Welch Z, O'Shaughnessey K and Hoeppner J: Autologous protein solution inhibits MMP-13 production by IL-1 $\beta$ and TNF $\alpha$-stimulated human articular chondrocytes. J Orthop Res 29: 1320-1326, 2011.

44. Liacini A, Sylvester J, Li WQ and Zafarullah M: Inhibition of interleukin-1-stimulated MAP kinases, activating protein-1 (AP-1) and nuclear factor kappa B (NF-kappaB) transcription factors down-regulates matrix metalloproteinase gene expression in articular chondrocytes. Matrix Biol 21: 251-262, 2002.

45. Saklatvala J: Inflammatory signaling in cartilage: MAPK and NF-kappaB pathways in chondrocytes and the use of inhibitors for research into pathogenesis and therapy of osteoarthritis. Curr Drug Targets 8: 305-313, 2007.

46. Roman-Blas JA and Jimenez SA: NF-kappaB as a potential therapeutic target in osteoarthritis and rheumatoid arthritis. Osteoarthritis Cartilage 14: 839-848, 2006.

47. Wehling N, Palmer GD, Pilapil C, Liu F, Wells JW, Müller PE, Evans $\mathrm{CH}$ and Porter RM: Interleukin-1beta and tumor necrosis factor alpha inhibit chondrogenesis by human mesenchymal stem cells through NF-kappaB-dependent pathways. Arthritis Rheum 60: 801-812, 2009. 